\title{
The effects of frenotomy on breastfeeding
}

\author{
Roberta Lopes de Castro MARTINELLI' ${ }^{1}$, Irene Queiroz MARCHESAN ${ }^{2}$, Reinaldo Jordão GUSMÃO ${ }^{3}$, Heitor Marques \\ HONÓRIO ${ }^{4}$, Giédre BERRETIN-FELIX ${ }^{5}$
}

\author{
1- Bauru School of Dentistry, University of São Paulo, Bauru, SP, Brazil. \\ 2- CEFAC, São Paulo, SP, Brazil. \\ 3- Department of ENT, School of Medical Sciences, State University of Campinas, Campinas, SP, Brazil. \\ 4- Department of Pediatric Dentistry, Orthodontics and Community Health, Bauru School of Dentistry, University of São Paulo, Bauru, SP, Brazil. \\ 5- Department of Speech-Language Pathology, Bauru School of Dentistry, University of São Paulo, Bauru, SP, Brazil.
}

Corresponding address: Roberta Lopes de Castro Martinelli - Avenida Ângelo Piva, 331 - Brotas - SP - Brazil - 17380-000 - Phone: 14-36532707 - e-mail: robertalcm@gmail.com

Submitted: September 1, 2014 - Modification: November 3, 2014 - Accepted: November 10, 2014

\section{ABSTRACT}

\begin{abstract}
A Ithough the interference of tongue-tie with breastfeeding is a controversial subject, The use of lingual frenotomy has been widely indicated by health professionals. Objective: To observe changes in breastfeeding patterns after lingual frenotomy concerning the number of sucks, pause length between groups of sucking and mother's complaints. Material and Methods: Oral yes/no questions about breastfeeding symptoms and sucking/ swallowing/breathing coordination were answered by the mothers of 109, 30 day old infants. On the same day the infants had their lingual frenulum assessed by administering a lingual frenulum protocol. After the assessment, all tongue-tied infants were referred for frenotomy; nevertheless, only 14 underwent the surgery. Of the 109 infants, 14 infants who did not have frenulum alterations were included as controls. Birth order and gender were the criteria for recruiting the control group. The tongue-tied infants underwent lingual frenotomy at 45 days of age. At the conclusion of the frenotomy, the infants were breastfed. At 75 days old, both groups - control and post-frenotomy - were reassessed. Before the reassessment the same oral yes/no questions were answered by the mothers of the 14 infants who underwent frenotomy. The mothers of the control group answered the questionnaire only at the time of the first assessment. Data were subjected to statistical analysis. Results: After frenotomy, the number of sucks increased and the pause length between sucking decreased during breastfeeding. The controls maintained the same patterns observed in the first assessment. From the questionnaire answered by the mothers of the 14 tongue-tied infants, at 30 days and 75 days, we observed that the symptoms concerning breastfeeding and sucking/swallowing/breathing coordination were improved after lingual frenotomy Conclusions: after lingual frenotomy, changes were observed in the breastfeeding patterns of the the tongue-tied infants while the control group maintained the same patterns. Moreover, all symptoms reported by the mothers of the tongue-tied infants had improved after frenotomy.
\end{abstract}

Keywords: Lingual frenum. Ambulatory surgical procedures. Breast feeding. Weaning. Signs and symptoms.

\section{INTRODUCTION}

The World Health Organization (WHO) ${ }^{16}$ has recommended that mothers exclusively breastfeed for the first 6 months of the child's life. The benefits of breastfeeding have been reported and the causes of precipitated weaning have been widely studied. Although lingual frenulum alteration (tongue-tie) has been considered as one of the causes for breastfeeding difficulties, it is a subject of much controversy among various healthcare professionals ${ }^{2,4-6,10}$. Tongue-tie occurs when a common minor embryologic tissue remnant causes restrictions in the normal movement of the tongue ${ }^{10}$.

Breastfeeding difficulties due to tongue-tie include ineffective latching, inadequate milk transfer and maternal nipple pain. According to 
several studies, lingual frenotomy is suggested when these complaints are reported ${ }^{2,4-6,10}$.

Benefits after frenotomy such as better latching, maternal nipple pain reduction, and maintenance of breastfeeding practices have been reported 2,4-6,10. Nevertheless, studies on the physiological aspects of sucking and on pause length between groups of sucking before and after lingual frenotomy were not found in the literature.

Two hypotheses are formulated: 1) lingual frenotomy improves the patterns of sucking and breastfeeding in infants with tongue-tie; 2) symptoms during breastfeeding reported by mothers decreased after lingual frenotomy.

\section{MATERIAL AND METHODS}

\section{Study design}

This was a prospective longitudinal study conducted with infants to observe changes in breastfeeding patterns after lingual frenotomy concerning the following items: number of sucks, pause length between groups of sucking and complaints from mothers.

\section{Subjects}

109 infants born at the Santa Therezinha Hospital in Brotas - São Paulo, Brazil from January to May 2011 had their lingual frenulum assessed by a speech-language pathologist from a public health care service in Brotas.

After the assessment, all tongue-tied infants were referred for frenotomy; however, only 14-10 males and 4 females - underwent the surgery. For different reasons many families decided not to have the surgery. Of the 109 infants, the 14 infants- 10 males and 4 females - that did not have any lingual frenulum alteration were included as controls. Birth order and gender were the criteria for recruiting the control group. All infants were being breastfed. All infants were first assessed at 30 days old and then reassessed at 75 days old.

Perinatal complications, craniofacial anomalies and visible genetic syndromes were the exclusion criteria.

An informed consent form was given to the parents prior to frenotomy and they were made aware of the how the procedure would be carried out. The research was approved by CEFAC's Ethics Committee (019/10).

\section{Evaluation and intervention procedures}

Previous to assessment, oral yes/no questions about breastfeeding symptoms and sucking/ swallowing/breathing coordination were answered by the mothers of 109 infants at 30 days old. On the same day the infants had their lingual frenulum assessed by administering the lingual frenulum protocol proposed by Martinelli, Marchesan and Berretin-Felix ${ }^{11,12}(2012,2013)$ before and during breastfeeding. The protocol consists of a clinical history evaluation, anatomo-functional evaluation and non-nutritive and nutritive sucking evaluations.

This study considered the assessment of the number of sucks in each one of the three first groups of sucking. One group of sucking consists of a number of sucks in a row followed by pause. The average of sucks of the three first groups of sucking

Table 1- Average values of the measurement related to the number of sucks and length of pauses during breast feeding for both groups: infants with and without lingual frenulum alteration (tongue-tie)

\begin{tabular}{|c|c|c|c|}
\hline & $\begin{array}{l}\text { Group with } \\
\text { tongue-tie }\end{array}$ & Control group & $\begin{array}{l}\text { Statistical analysis } \\
\text { ( } \neq \text { between groups) }\end{array}$ \\
\hline \multicolumn{4}{|l|}{$\begin{array}{l}\text { The average number of sucks in each one of the } \\
\text { three first groups of sucking before sugery }\end{array}$} \\
\hline Average at 30 days of age & $19.36 \pm 13.02$ & $55.76 \pm 21.00$ & $p=0.005^{*}$ \\
\hline \multicolumn{4}{|l|}{$\begin{array}{l}\text { The average number of sucks in each one of the } \\
\text { three first groups of sucking after surgery }\end{array}$} \\
\hline Average at 75 days of age & $53.76 \pm 7.99$ & $54.50 \pm 20.88$ & $p>0.05$ \\
\hline Statistical analysis ( $\neq$ between moments) & $p<0.001^{*}$ & $p>0.05$ & \\
\hline \multicolumn{4}{|l|}{$\begin{array}{l}\text { Pause length measurement before surgery } \\
\text { calculeted in seconds }\end{array}$} \\
\hline Average at 30 days of age & $6.14 \pm 2.47$ & $3.00 \pm 0.63$ & $\mathrm{p}<0.001^{*}$ \\
\hline \multicolumn{4}{|l|}{$\begin{array}{l}\text { Pause length measurement after surgery } \\
\text { calculated in seconds }\end{array}$} \\
\hline Average at 75 days & $3.88 \pm 0.88$ & $3.30 \pm 0.67$ & $p>0.05$ \\
\hline Statistical analysis ( $\neq$ between moments) & $p=0.013^{*}$ & $p>0.05$ & \\
\hline
\end{tabular}

*statistically significant difference 
was calculated. Pause lengths between groups of sucking were calculated in seconds using a chronometer and the average pause length between the three first groups of sucking was calculated.

The result of the assessment indicated the infants with and without lingual frenulum alteration. After the assessment, all tongue-tied infants were referred for frenotomy; nevertheless, only 14 underwent the surgery. The tongue-tied infants underwent lingual frenotomy at 45 days of age. All surgeries were performed by an otorhinolaryngologist, who decided to perform the procedures with a topical anesthetic. The infant's tongue was lifted upwards with a grooved director. Sterile scissors were used to release the lingual frenulum. Suture was not necessary. At the conclusion of the procedure, the infants were immediately breastfed.

At 75 days of age, both groups - control and post-frenotomy - were reassessed. Before the reassessment the same oral yes/no questions were answered by the mothers of the 14 infants who underwent frenotomy. The mothers of the control group answered the questionnaire only during the first assessment.

The questionnaire contained the following questions: a) Is time between feedings less than one hour? b) Does the infant sleep less than 2 hours between feedings? c) Does the infant alternate between sucking and sleeping during breastfeeding? d) Does the infant feel tired during breastfeeding? e) Does the infant suck a little and then stop for a long rest period? f) Does the infant chew on the nipple during breastfeeding? g) Does the infant have a strong suck? h) Does the infant frequently make tongue clicking noises during breastfeeding? i) Does the infant slip off of the nipple during breastfeeding? j) Do you have nipple pain during breastfeeding? k) Does the infant frequently make sounds while swallowing the milk during breastfeeding? I) Does the infant frequently choke during breastfeeding? m) Does the infant frequently get hiccups immediately after

Table 2- Questionnaire answers: percentage of symptoms reported by the mothers of the 28 infants

\begin{tabular}{|c|c|c|c|}
\hline \multirow[t]{2}{*}{ SYMPTOMS } & \multirow{2}{*}{$\begin{array}{c}\text { Control Group } \\
\text { Initial Q }\end{array}$} & \multicolumn{2}{|c|}{$\begin{array}{l}\text { Group with lingual frenulum } \\
\text { alteration }\end{array}$} \\
\hline & & Initial Q & Final Q \\
\hline & $\%$ Yes & $\%$ Yes & $\%$ Yes \\
\hline \multicolumn{4}{|l|}{ BREASTFEEDING } \\
\hline Is time between feedings less than one hour? & 0 & 92,85 & 0 \\
\hline Does the infant sleep less than 2 hours between feedings? & 0 & 85.71 & 0 \\
\hline $\begin{array}{l}\text { Does the infant alternate between sucking and sleeping during } \\
\text { breastfeeding? }\end{array}$ & 0 & 64.28 & 0 \\
\hline Does the infant feel tired during breastfeeding? & 0 & 100 & 0 \\
\hline $\begin{array}{l}\text { Does the infant suck a little and then stop a long time for } \\
\text { resting? }\end{array}$ & 0 & 100 & 0 \\
\hline Does the infant chew the nipple during breastfeeding? & 7.14 & 50 & 0 \\
\hline Does the infant have a strong suck? & 35.71 & 85.71 & 0 \\
\hline $\begin{array}{l}\text { Does the infant frequently click the tongue during } \\
\text { breastfeeding? }\end{array}$ & 14.29 & 64.28 & 0 \\
\hline Does the infant slip off the nipple during breastfeeding? & 0 & 71.42 & 0 \\
\hline Do you have nipple pain during breastfeeding? & 21.43 & 42.85 & 0 \\
\hline \multicolumn{4}{|l|}{ SUCKING/SWALLOWING/BREATHING COORDINATION } \\
\hline $\begin{array}{l}\text { Does the infant frequently make sounds while swallowing the } \\
\text { milk during breastfeeding? }\end{array}$ & 21.43 & 50 & 0 \\
\hline Does the infant frequently choke during breastfeeding? & 28.57 & 57.14 & 0 \\
\hline $\begin{array}{l}\text { Does the infant frequently get hiccups immediately after } \\
\text { breastfeeding? }\end{array}$ & 21.43 & 50 & 7.14 \\
\hline Does the infant frequently cough during breastfeeding? & 0 & 7.14 & 0 \\
\hline $\begin{array}{l}\text { Does the infant frequently regurgitate immediately after } \\
\text { breastfeeding? }\end{array}$ & 21.43 & 14.28 & 0 \\
\hline
\end{tabular}

Initial Q=Initial Questionnaire; Final Q=Final Questionnaire 
breastfeeding? $\mathrm{n}$ ) Does the infant frequently cough during breastfeeding? o) Does the infant frequently regurgitate immediately after breastfeeding?

\section{Statistical analysis}

The quantitative data was subjected to statistical analysis using the Repeated Measures Analysis of Variance test followed by Tukey test - which is a multiple comparison test - considering group factor as an independent variable and time (first and second evaluation) as a dependent variable. The qualitative data had a descriptive analysis. The data's statistical analysis had a significance level of $5 \%(p<0.05)$.

\section{RESULTS}

After lingual frenotomy, the number of sucks increased and the pause length between sucking groups decreased during breastfeeding as shown in Table 1.

From the questionnaire answered by the mothers of the 14 tongue-tied infants, at 30 days and 75 days, we observed that the symptoms concerning breastfeeding and sucking/swallowing/ breathing coordination were improved after the lingual frenotomy as shown in Table2.

Before lingual frenotomy, the main symptoms reported were: fatigue during breastfeeding, long pauses between sucks for resting, short time between feedings (less than one hour), strong sucks, and less than two-hours of sleep between feedings. Other symptoms also reported were: slipping off the nipple, chewing on the nipple, hiccups, sounds during breastfeeding, nipple pain, regurgitation and coughing. After lingual frenotomy, the only symptom reported by one of the mothers was hiccups. The other symptoms reported by the mothers before frenotomy were absent after frenotomy as shown in Table 2.

The controls maintained the same breastfeeding patterns observed in the first assessment.

\section{DISCUSSION}

Although the interference of alterations to the lingual frenulum with breastfeeding is a subject of controversy, lingual frenotomy has been widely indicated by healthcare professionals, mainly due to government breastfeeding campaign $\mathrm{s}^{5-6,8,16}$.

Various prospective cohort studies and randomized trials were published in the last 15 years, reporting nipple pain and breastfeeding difficulties $2,4,7,9$. Despite the importance of breastfeeding, studies correlating tongue-tie to the number of sucks and pause length between sucking groups after frenotomy were not found in the literature.
The findings of this study clearly demonstrated improvements in sucking after lingual frenotomy, and confirmed the importance of administering a lingual frenulum evaluation protocol for early frenotomy indication.

Better latching and breastfeeding quality as well as increasing the time between feedings after frenotomy have been reported in the literature ${ }^{13-15}$. Those findings may be explained by the fact that after lingual frenotomy, the movements of the tongue are released; consequently, the number of sucks increased and the pause length between sucking groups decreased. The results of this study, shown in Table 1, are in agreement with the literature ${ }^{10,13-15}$.

Moreover, the literature reports that independently of the frenulum, ineffective latching may be caused by characteristics of the nipple ${ }^{12}$.

Before frenotomy the mothers of the tonguetied infants had reported a short time between feedings - less than 1 hour - reduced feeding time, infant fatigue during breastfeeding, and inefficient milk transfer and sleep, which caused stress for both the mother and the infant. The improvement of the symptoms reported by mothers after the surgery confirmed the positive results of the lingual frenotomy. Although mothers were aware of the procedure, thus introducing a significant bias, the results demonstrated were in agreement with literature ${ }^{2}$. Moreover, those findings are in agreement with the reports stating that breastfeeding difficulties diminish after lingual frenotomy $2-4,6,8,10,12-15$.

By administering the existing lingual frenulum assessment protocols found in literature ${ }^{1,11-12}$, speech-sanguage pathologists, mainly orofacial motricity/dysphagia specialists, should be able to assess and diagnose tongue-tie interfering with breastfeeding in order to avoid precipitated weaning. Breastfeeding is a key aspect of maternal, newborn and child health because it provides all the nutrients and antibodies required for healthy development. Moreover, breastfeeding is also beneficial for the emotional connection between mother and child ${ }^{16}$.

\section{CONCLUSIONS}

After lingual frenotomy, the tongue-tied infants displayed changes in breastfeeding patterns - the number of sucks increased and the pause length between groups of sucking decreased - while the control group maintained the same breastfeeding patterns. Moreover, all symptoms reported by the mothers of tongue-tied infants were improved after lingual frenotomy. 


\section{Conflict of interest}

There was no financial support or funding for this study. The authors have no financial obligations to disclose and there were no conflicts of interest.

\section{REFERENCES}

1- Ballard JL, Auer CE, Khoury JC. Ankyloglossia: assessment, incidence, and effect of frenuloplasty on the breastfeeding dyad. Pediatrics. 2002;110(5):1-6.

2- Berry J, Griffiths M, Westcott C. A double-blind, randomized, controlled trial of tongue-tie division and its immediate effect on breastfeeding. Breastfeed Med. 2012;7(3):189-93.

3- Bowley DM, Arul GS. Fifteen-minute consultation on the infant with a tongue-tie. Arch Dis Child Educ Pract Ed. 2014;99(4):127-9.

4- Buryk M, Bloom D, Shope T. Efficacy of neonatal release of ankyloglossia: a randomized trial. Pediatrics. 2011;128(2):280-8. 5- Cho A, Kelsberg G, Safranek S. Clinical inquiries. When should you treat tongue-tie in a newborn? J Fam Pract. 2010;59(12):712a-b.

6- Constantine AH, Williams $\mathrm{C}$, Sutcliffe AG. A systematic review of frenotomy for ankyloglossia (tongue tie) in breast fed infants. Arch Dis Child. 2011;96(Suppl 1):A62-3.

7- Dollberg S, Manor Y, Makai E, Botzer E. Evaluation of speech intelligibility in children with tongue-tie. Acta Pædiatrica. 2011;100:e125-7.
8- Edmunds J, Miles SC, Fulbrook P. Tongue-tie and breastfeeding: a review of the literature. Breastfeed Rev. 2011;19(1):19-26. 9- Hogan M, Westcott C, Griffiths M. Randomized, controlled trial of division of tongue-tie in infants with feeding problems. J Paediatr Child Health. 2005;41:246-50

10- Knox I. Tongue tie and frenotomy in the breastfeeding newborn. Neo Reviews. 2010;11(9):513-9.

11- Martinelli RL, Marchesan IQ, Berretin-Felix G. Lingual frenulum protocol with scores for infants. Int J Orofacial Myology. 2012;38:104-12.

12- Martinelli RL, Marchesan IQ, Berretin-Felix G. Lingual frenulum evaluation protocol for infants: relationship between anatomic and functional aspects. Rev CEFAC. 2013;15(3):599-610.

13- Ngerncham S, Laohapensang M, Wongvisutdhi T, Ritjaroen $Y$, Painpichan N, Habularb $P$, et al. Lingual frenulum and effect on breastfeeding in Thai newborn infants. Paediatr Int Child Health. 2013;33(2):86-90.

14- O'Callahan C, Macary S, Clemente S. The effects of officebased frenotomy for anterior and posterior ankyloglossia on breastfeeding. Int J Pediatr Otorhinolaryngol. 2013:77(5):827-32. 15- Sethi N, Smith D, Kortequee S, Ward VM, Clarke S. Benefits of frenulotomy in infants with ankyloglossia. Int J Pediatr Otorhinolaryngol. 2013;77(5):762-5.

16- World Health Organization. World Breastfeeding Week 2012 [online]. 2012 Aug. [cited 2014 Sept 1]. Available from: http://www.who.int/pmnch/media/news/2012/2012_world_ breastfeeding_week/en/. 